\title{
Effects of practicing in remote Japanese islands on physicians' control of negative emotions: A qualitative study
}

\author{
Ryuichi Ohta ${ }^{1}$, and Makoto Kaneko ${ }^{2,3}$ \\ ${ }^{1}$ Unnan City Hospital, Japan \\ ${ }^{2}$ Musashikoganei Clinic, Japanese Health and Welfare Co-operative Federation, Japan \\ ${ }^{3}$ Division of Clinical Epidemiology, Jikei University School of Medicine, Japan
}

\begin{abstract}
Objective: To explore how rural physicians practicing in the remote islands of Okinawa, Japan experience and manage their negative emotions.

Materials and Methods: We conducted semi-structured interviews with doctors who had worked in a clinic on a remote island in Okinawa prefecture for 2 years. The interviews were conducted using an Internet video conferencing system, and were recorded and transcribed. The transcribed data were then analyzed using the Steps Coding and Theorization method as a framework.

Results: All four participants were male. The mean interview time was 61 minutes. In the category of induction of negative emotions, we extracted five themes: differences in recognition between rural physicians and patients, invasion of professionalism, suppression by one's role as a rural physician, discordance with multiple occupations, and relationships with unfamiliar hospital physicians. In the category of controlling negative emotions, we also extracted five themes: time flow, reflection, acceptance of islanders' characteristics, and growth through their role.

Conclusion: Rural physicians in the remote islands of Okinawa experienced negative emotions in relation to patients, other islanders, and medical staff. They deepened their understanding of the islanders, including the cultural background, over time and through discussion and reflection with other medical professionals. In this way, they realized their potential for growth and how to control negative emotions. Thus, rural physicians may be able to effectively control their negative emotions through recognizing temporal changes in human relations and their own adaptation to the remote island life.
\end{abstract}

Received: March 30, 2017

Accepted: July 7, 2017

Correspondence: Ryuichi Ohta, MD, Unnan City Hospital, 96-1 Iida, Daito-cho, Unnan city, Shimane 699-1221, Japan

E-mail: ryuichiohta0120@gmail.com

This is an open-access article distributed under the terms of the Creative Commons Attribution Non-Commercial No Derivatives (by-nc-nd) License $<$ http://creativecommons.org/licenses/by-nc-nd/4.0/>.
Key words: negative emotions, remote island, place attachment, Okinawa, Japan

(J Rural Med 2017; 12(2): 91-97)

\section{Introduction}

Physicians often experience mental stress, including negative emotions, as a result of their interactions with patients and other medical staff ${ }^{1)}$. A negative emotion is defined as "an emotion that emerges through mutual relations with other people in the process of communication, such as anxiety, disgust, discomfort, horror, anger, confusion, and depression" ${ }^{2-4)}$. Physicians may experience negative emotions when caring for patients with poor therapeutic adherence or colleagues with whom they have not established good relations. Negative emotions can have a strong influence on their clinical practice, in particular the quality of medical treatment, thus leading to deterioration in medical care, misdiagnosis, and burnout ${ }^{1)}$. More specifically, around $40 \%$ of physicians reported that the quality of their medical treatment had decreased because of experiencing excessive negative emotions such as anger during medical treatment ${ }^{5)}$. Negative emotions were also found to lead to biases in diagnosing patients, thus leading to misdiagnosis; an awareness of such bias can improve the quality of medical treatment ${ }^{6,77}$. Workplace stress can also increase physicians' mental burden, thus leading to burnout. However, the influence of such stress is greatly dependent on methods of coping and personality ${ }^{8,9}$.

Negative emotions can also have a substantial influence on primary care - primary care physicians tend to experience considerable stress in relation to their interactions with other physicians. However, if they can learn to control their emotions, they might be able to reduce feelings of stress ${ }^{10)}$. 
This is particularly important for navigating the highly complex environment and nature of practice in primary care ${ }^{11}$. Japanese researchers have demonstrated that general practitioners in Japan tend to experience negative emotions when their own values are discordant with those of their patients, or when they try to approach patients' ambiguous expectations. To control said emotions, physicians often employ avoidance or acceptance strategies ${ }^{12}$.

Learning to control one's emotions is regarded as especially critical for physicians on remote islands, although the methods used for such control may depend on the island's environment and the physician's own characteristics ${ }^{13}$. Physicians practicing in the remote island clinics of Okinawa, Japan tend to work alone, be young, and have only around four to six years of experience as a physician. Furthermore, their situation with regard to emotional control is rather unique in that they must control their emotions while examining patients as well as building relationships with the other islanders. However, there not yet been a study on emotional control practices among physicians working at remote island clinics in Japan. Therefore, we aimed to clarify the situations in which these physicians experience negative emotions and how they manage these emotions.

\section{Methods}

\section{Participants and setting}

Participants were physicians who had worked at remote island clinics in Okinawa for at least 2 years between April 2013 and March 2015. Purposive sampling was performed to recruit participants. Their workplaces were isolated island clinics in which only one physician, one nurse, and one clerk worked. The population of the remote islands ranged from 240 to 1,500 people, and each clinic was the only medical institution on its island. These clinics were open from 8:30 am to $5 \mathrm{pm}$. To provide overtime medical care, the physicians had mobile phones that they used to interact with and gather information from islanders who were experiencing an emergency. The physicians always carried their mobile phones in order to prepare for emergency situations. Patients who could not be easily treated at the clinics were transferred to mainland hospitals in Okinawa through prefectural airborne medical services or the Self-Defense Forces (SDF). The transportation methods used differed depending on the distance between the clinic and the mainland and the time at which patients began experiencing the emergency. For islands near mainland Okinawa, a prefectural airborne medical service was used during the daytime, whereas the SDF was contacted for emergencies occurring at nighttime or at clinics far away from the mainland.

\section{Data collection}

We conducted semi-structured interviews with each participant. The interviews were performed over an Internet video conferencing system using an interview guide. The interview guide consisted of 4 questions: "Tell me, in detail, about the situations that made you experience negative emotions", "How did you respond to those negative emotions?", "Do you experience negative emotions that you believe are still difficult to control?", and "How do you want to address future negative emotions?" We gave a copy of the interview guide to participants in advance. We employed the abovementioned operational definition of negative emotions (see the Introduction), which was presented to the participants in advance. The lead author (RO), who also worked as a physician at a remote island clinic in Okinawa Prefecture, interviewed all participants. We recorded the contents of the interviews using an IC recorder and transcribed the contents of the interview. We outlined the research to participants before starting the interviews, and obtained their informed consent.

\section{Data analysis}

The transcripts were analyzed according to the Steps for Coding and Theorization (SCAT) method ${ }^{14}$. This is a sequential and thematic qualitative data analysis technique that involves several coding steps, ranging from open to selective. A storyline is then compiled by using the codes derived from selective coding, and theories are derived from this storyline. We selected this qualitative method because of its explicit process of analysis, the fact that it relies on theoretical coding, and its efficiency and validity in theorizing from relatively small-scale data. The lead author (RO) performed each step of the analysis and a co-author (MK) read the transcripts and results of the analysis as an independent auditor to ensure the dependability and confirmability of the analysis. The co-author (MK) also had experience as a remote island clinic physician in Okinawa. Through these processes, we attempted to build a theory on the negative emotional control of physicians practicing at remote island clinics.

\section{Ethical considerations}

In accordance with the Declaration of Helsinki, we requested interviewees to voluntarily participate and to give their written informed consent. We also informed them that they had the right to refuse cooperation at any time if they experienced any discomfort. This research was approved by the Medical Ethics Committee of the Okinawa Prefectural Southern Medical Center/Children's Medical Center (Approval number 2015-10). 
Table 1 Participant characteristics

\begin{tabular}{ccccc}
\hline Participant & Age (years) & Sex & Total experience (years) & Prior experience (years) \\
\hline 1 & 29 & Male & 5 & 3 \\
2 & 29 & Male & 5 & 3 \\
3 & 30 & Male & 5 & 3 \\
4 & 29 & Male & 5 & 3 \\
\hline
\end{tabular}

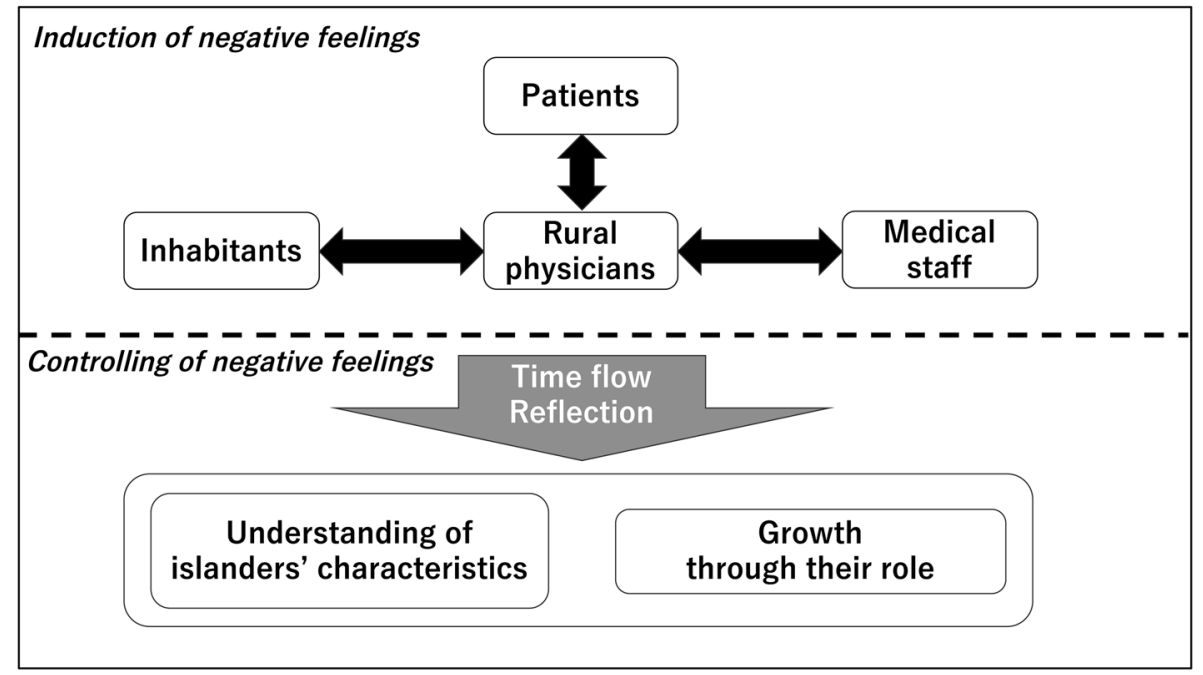

Figure 1 Conceptual framework on negative emotions of remote island clinic physicians. Black arrows indicate a conflict in relationships.

\section{Results}

A total of four physicians who had worked at remote island clinics affiliated with an Okinawa prefectural hospital for 2 years participated in this study. The average of time to complete the interviews was 61 minutes. All of the participants were male and had six years of experience as a practicing physician, and all had been assigned to each remote island clinic in their fourth year as a physician (Table 1). Their average age was 29 years. The conceptual framework of this study is depicted in Figure 1.

\section{Induction of negative emotions}

- Excessive patient needs: A variety of patients visited the clinics, all of whom had various, and occasionally excessive, needs. Some of these needs did not require medical intervention to satisfy. For instance, even when physicians explained to patients the importance of using antibiotics appropriately, patients on remote islands still demanded them:

'It was when the patient said, 'I want antibiotics.' Even when I think that patients suffer from viral infections, they do not accept the idea easily. I feel negative emotions at that time."
However, because the clinics were the only medical institutions on these remote islands, physicians felt strong pressure from patients, and thus could not help but give in to their demands. This was partially because they had worked only at a general hospital and had never practiced medicine by themselves. Some also reported experiencing negative emotions when patients' families criticized their practices as physicians:

"Although I intended to respond appropriately to a patient who had alcohol problems, the family pointed out that my attitude towards teaching patients was poor, and they also told me 'You should say it more strongly. The patient will not stop drinking unless you do.,'”

In performing patient-centered medical care, physicians found it difficult to deal with all patients' problems on their own. Although behavioral modification of patients is an essential ability for physicians, there was insufficient cooperation with other professions or other specialized medical institutions on the islands, which increased the burden of care on physicians.

- Invasion of professionalism: The professionalism that they had cultivated in the general hospital became a major obstacle when practicing in the remote islands. At the hos- 
pital, they were forbidden to receive gifts from patients. By contrast, on the islands, they frequently received vegetables and dishes that the islanders made, which forced them to go against their own professionalism. They also experienced strong negative emotions in response to some islanders' attitude of seeking returns for these gifts:

"When working on the island, I was offered some groceries from patients, such as fruits and so on. Although most people don't ask for returns [for such gifts], some of them expected returns, which could be a difficult situation for rural physicians. Some got angry when I refused their offers, so I found it difficult to handle the situations."

"When a patient who visited the clinic at midnight often did good things for me, I grew concerned about the [other islanders'] attitudes toward me. I felt they thought it natural."

In this way, they were forced to reconsider their professionalism in order to build relationships on the remote islands, as well as to build patient-physician relations. Furthermore, they experienced confusion because they could not refuse the patients seeking returns.

- Conflict between various occupations: When physicians must practice medicine on their own, they must build cooperative relationships with workers in diverse occupations. The participants confessed that they did not fully understand the environments of these other workers (and believed the opposite was true as well), and felt little responsibility for the other workers' actions. They also reported a sense of helplessness in working on the remote islands:

"Some employees of the nursing home are not familiar with medical care. Of course, I know that they are motivated in their work. However, when a facility user worsened, I experienced negative emotions towards them [the employees]. There was a time when one of the employees was worried about an elderly man who had a little sputum and frequently contacted me. At that time, I thought honestly, 'What do you want me to do?' The elderly man had a common cold, and we could only treat the symptoms. The nursing facility staff member seemed to think that the man might die because of this sputum. And they felt they had to take responsibility and seemed to contact me frequently in order to escape this responsibility. But even if I received that report, it was difficult for me to take responsibility for it."

In other words, the physicians strove to understand their environment and the capabilities of other workers, but experienced negative emotions when the workers from these other occupations frequently burdened them with problems that could not be solved only through medical treatment.

- Framework of a doctor: All the physicians were liv- ing as the sole doctor on the remote islands. Because of the small communities, wherever they were on the island, they could not escape their role as physician, and experienced negative emotions as a result:

"When I was drinking alcohol, the inhabitants sometimes stared at me. Or when I was outside and walking on the main street on holidays, people asked me about their health. These were painful experiences for me. At any given time, I felt that I am seen as [only] a doctor."

"When I was taking part in an athletic meet, someone fell down on the ground and got injured. At that time, most of the islanders were looking at me. After all, I learned that everyone was always looking at me as a doctor."

- Unfamiliar relationships with hospital doctors: Rural island clinics were often unable to complete medical treatment alone, making it necessary to refer patients to the hospital depending on the type and severity of the disease. Remote island physicians often had to introduce patients to other physicians whom they did not know well. This led to poor communication between physicians, and, consequently, negative emotions:

"I felt negative emotions whenever I had to exchange information about my patients. I could not exchange information well... I did not understand the hospital physician's ideas well. Clinic doctors and hospital doctors don't have the same ideas about their patients' treatments. We might be thinking only from our own point of view."

"When I transferred a patient to the hospital, I was asked by a doctor in the hospital, 'Is it possible for you to see him on the remote island?' I felt negative emotions [then]. I thought they didn't understand us."

\section{Controlling negative emotions}

- Time flow: Rural physicians reported having more opportunities to interact with the islanders while they were adapting to living on the remote islands. This helped them build good patient-doctor relationships over time. The greater understanding of their patients' backgrounds such relationships afforded helped to alleviate their negative emotions:

"At first, I felt that some patients were very impolite. I didn't feel good [because of that]. But, well, in one or two years, my impression of them drastically changed. I knew that some of them were working very hard on the sugarcane farm or some didn't have family on the island, and so on. By listening to [them talk about] their real life, my negative feelings disappeared spontaneously."

"When I had lived for a long time on the island, I could understand patient information as a real experience. In- 
evitably, I learned about a variety of problems on the island and my affinity with the island developed. I had realized that there were a lot of problems that I could not solve easily with medicine."

The remote island clinic physicians reported being more tolerant of patients' and families' excessive complaints through developing a deeper understanding of the patients over time. Additionally, they learned how to concentrate on the problems with which they could cope by controlling their psychological distance from patients and deciding on the appropriate scope of medical care.

- Reflection: Because these physicians engaged in medical care on remote islands, they had many opportunities to collaborate with professionals from multiple occupations when responding to patients or conducting regional health promotion. Through these activities, they were able to establish good professional relationships with others, and these relationships afforded them opportunities to reflect on various medical cases or their own experiences in their own jobs together:

"When discussing medical problems with other staff, I frequently asked many professionals, 'What do you think about this?' In that way, I could understand in depth what was happening, and I think it was important for third parties to look at my experiences objectively. Whatever the opinion of other professions, I feel that the negative emotions are somehow alleviated."

"Dialogue with other remote island doctors was also important. We could talk with each other immediately with a video phone. [Negative] emotions might be relieved by exchanging ideas."

Physicians learned how to control their negative feelings by sharing with these other professionals their own emotional changes, as well as by reflecting on these changes and attempting to acquire a more objective perspective. Additionally, by talking about the problems of remote island medical treatment in retrospect, they obtained opportunities to solve problems, which in turn enhanced their motivation to engage in remote island medical care.

Acceptance of islanders' characteristics: The longer they lived on the remote islands, the better the physicians understood not only the health conditions of the islanders but also their ways of thinking and thoughts about their lives. Although they initially examined patients using the perspectives cultivated while working in hospitals, adapting to the remote island life helped them to better adopt the perspective of the islanders:

"I was getting used to the customs of the island and their way of thinking. So, now, if they say something that differs from my common sense, I don't experience any negative feelings. I think I am becoming a member of the society here, maybe."

"The islanders are acting according to their own background. They have acquired it over a long time. They can't change it. After my experiences in a remote island, I have noticed this. Although I [sometimes] must strongly say something to ensure patients' health, I [realize that I] should adjust my explanation to them"

By understanding the islanders' cultural background, physicians were able to consider patients from perspectives previously unknown to them. While it was not easy for them to fully understand this cultural background, a partial understanding was enough to help them control their negative emotions.

- Growth through their role: As noted above, the remote island physicians constantly felt that the islanders viewed them only as a doctor. While it began as a source of considerable stress, as life on the remote islands passed, this role began to benefit them:

"In my normal life as an islander, I was always aware of being seen as a doctor and acting on it all the time. However, after I had arrived on the island and it gradually became the norm as time went by, I began drinking less alcohol naturally. By thinking that I was being seen [as a doctor], I think that I had begun to avoid doing sloppy things as a doctor, even when off the island."

"I gradually became used to the islanders' eyes. But on the contrary, it made me feel that the islanders were relying on me. Thanks to this, I was able to improve my efforts as a doctor."

Participants realized that being constantly watched as a physician led not only to negative emotions but also to their own growth. This improved their own medical treatment on the island as well as their attitudes towards life.

\section{Discussion}

This study determined that, throughout their two years of working on a remote island clinic, physicians experienced negative emotions as a result of problems with patient-physician relations, regional cooperation, and adapting to life as an islander. However, they were able to control these emotions through building trusting relationships based on deep connections with the islanders and community health organizations, as well through understanding the islanders' characteristics over time.

The remote island clinic physicians in this study formed human connections through their continued involvement with patients in a closed area. This gave rise to a mutual understanding with the islanders, which made them more conscious of the patients' backgrounds than the diseases. Understanding patient backgrounds may lead to better 
communication with patients, which can then reduce physicians' stress ${ }^{15)}$. In this case, this understanding could help them control their emotions. Furthermore, by living in the same way as the islanders, they began considering not only their values as physicians but also as islanders; in this way, they began making decisions from the perspectives of the islanders, even when it pertained to medical treatment. Previous studies have indicated that people develop a "place attachment" to regions by living there for a certain period, which in turn might increase their willingness to work in the region ${ }^{16}$. The emotional control that physicians developed through an understanding of the islanders' nature and the construction of human relationships with residents might be explained by this place attachment. Furthermore, improving patients' attachment to the physician may help to benefit the physician-patient relationship, which can help reduce remote island physicians' negative emotions ${ }^{17}$. Overall, we believe that physicians' living as both islander and doctor helped to improve their attachment to the islands, which in turn helped them control their emotions.

On the other hand, as their relationships with islanders strengthened, they had to make increasingly greater concessions to their own professionalism. In other words, in living for a long period in such a closed environment, as one of the islanders, they felt that the boundary between their identity as a doctor and their identity as an islander became ambiguous. They felt trapped in the role of "doctor" when on the island, causing them further stress. However, through reflections of the difficulties in their field compared with other professions, they could control their negative emotions and realize their growth. Their experiences may be considered a quantum leap, which makes it possible for learners to improve their abilities drastically through difficult challenges and subsequent reflection ${ }^{18,19)}$. Although remote island clinic physicians may experience many challenges in their solo practice, it is possible that constant reflection may lead to their continual growth and acquiring better way to control negative emotions.

A limitation of this research is that physicians' negative emotion control might have depended on their environments - research has shown that human emotional control is affected by both environmental and personal factors, and it varies greatly among physicians ${ }^{20)}$. Moreover, the number of subjects was small. Nevertheless, we attempted to interview physicians from diverse environments. Another limitation is the possibility of biased results because interviewees were all from the same generation. Interviewing multiple generations of physicians in the future might help develop the concepts identified herein.

\section{Conclusion}

The remote island physicians were able to control their negative feelings that resulted from living an isolated island life through developing a human connection with the islanders and achieving a greater understanding of islanders' backgrounds over time. For physicians to control their emotions while practicing in remote places, they must be able to accept the characters of the residents and temporal changes in their feelings.

Conflict of Interest: The authors state that they have no conflict of interest.

\section{Acknowledgments}

We would like to thank all the rural physicians that participated in this research and Akira Shimabukuro, who gave us much advice in writing this paper.

\section{References}

1. Firth-Cozens J. Doctors, their wellbeing, and their stress. BMJ 2003; 326: 670-671. [Medline] [CrossRef]

2. Saito K. A questionnaire survey of the role of emotion of nurse in the relationship between patients and nurses. Clin Nurs 1999; 25: 1854-1859 (in Japanese).

3. Nishimoto E. Nursing the patient who is apt to hold the negative feeling. Jpn Psychiatr Nurs Assoc 2003; 47: 148-151 (in Japanese).

4. Matsuura E. Ethical conflict of nurses with negative feelings towards patients. J Japan Acad Nurs Admin Policies 2010; 14: $77-84$.

5. Firth-Cozens J, Greenhalgh J. Doctors perceptions of the links between stress and lowered clinical care. Soc Sci Med 1997; 44: 1017-1022. [Medline] [CrossRef]

6. Trowbridge RL. Twelve tips for teaching avoidance of diagnostic errors. Med Teach 2008; 30: 496-500. [Medline] [CrossRef]

7. Phua DH, Tan NC. Cognitive aspect of diagnostic errors. Ann Acad Med Singapore 2013; 42: 33-41. [Medline]

8. Jones DL, Tanigawa T, Weiss SM. Stress management and workplace disability in the US, Europe and Japan. J Occup Health 2003; 45: 1-7. [Medline] [CrossRef]

9. McManus IC, Keeling A, Paice E. Stress, burnout and doctors attitudes to work are determined by personality and learning style: a twelve year longitudinal study of UK medical graduates. BMC Med 2004; 2: 29-40. [Medline] [CrossRef]

10. Elder N, Ricer R, Tobias B. How respected family physicians manage difficult patient encounters. J Am Board Fam Med 2006; 19: 533-541. [Medline] [CrossRef]

11. Miyata Y. Coping with uncertainty and complexity of primary care practice. J Japan Prim Care Assoc 2014; 37: 124-132 (in Japanese with English abstract). 
12. Yamashita M, Miyata Y. A qualitative study on general physicians' negative emotion towards their patients in a clinical setting. Jpn J Fam Med 2009; 15: 4-19.

13. Motomura K. Reflective practice and situational learning in island clinics. J Japan Prim Care Assoc 2012; 35: 165-167.

14. Otani T. "SCAT" A qualitative analysis method by four-step coding: easy startable and small scale data applicable process of theorization. Bull Grad School Edu Hum Dev Nagoya Uni 2007; 54: 27-44.

15. Dorr Goold S, Lipkin M Jr. The doctor-patient relationship: challenges, opportunities, and strategies. J Gen Intern Med 1999; 14(Suppl 1): S26-S33. [Medline] [CrossRef]

16. Suzuki H, Huzii S. Study on effects of place attachment on cooperative behavior local area. Infrastructure Plan Rev 2008;

\section{5: 357-362. [CrossRef]}

17. Berry LL, Parish JT, Janakiraman R, et al. Patients commitment to their primary physician and why it matters. Ann Fam Med 2008; 6: 6-13. [Medline] [CrossRef]

18. Goerke J. Taking the quantum leap: Nonprofits are now in business. An Australian perspective. Int J Nonprofit Volunt Sect Mark 2003; 8: 317-327. [CrossRef]

19. Qualters D. A quantum leap in faculty development: Beyond reflective practice. To Improve the Academy 1995; 14: 43-55.

20. Parkes KR. Coping in stressful episodes: the role of individual differences, environmental factors, and situational characteristics. J Pers Soc Psychol 1986; 51: 1277-1292. [Medline] [CrossRef] 